\title{
Analysis of the utilization of existing test data for phase-in substance registration under the Act on the Registration and Evaluation, etc. of Chemical Substances
}

\author{
Bong-In Choi ${ }^{1}$, Yeong-Don Kwak ${ }^{1}$, Yu-Mi Jung ${ }^{1}$, Byung-Taek Ryu ${ }^{1}$, Chang Gyun Kim ${ }^{2}$ \\ ${ }^{1}$ Environmental Safety Center, Korea Environmental Corporation, Incheon; ${ }^{2}$ Department of Environmental Engineering, Inha \\ Univercity, Incheon, Korea
}

\begin{abstract}
Objectives Approximately 2000 phase-in substances are subject to registration according to the Act on the Registration and Evaluation, etc. of Chemical Substances (KREACH), and the expected testing cost is 2.06 trillion Korean won assuming all the test data required for registration are acquired. The extent to which these enormous test costs can be reduced depends on the availability of existing data that can be used to meet the requirements of the K-REACH we examined the current availability of test data that can be used for chemical substance registration.

Methods We analyzed the possibility of utilizing the existing test data obtained from 16 reference databases for 369 of 518 kinds of phase-in substances subject to registration that were reported in last October 2014.

Results The physical and chemical properties were available for $57.1 \%$ of substances, whereas data regarding human hazards and environmental hazards were available at considerably lower rates, $8.5 \%$ and $11.8 \%$, respectively.

Conclusions Physical and chemical properties were available for a fairly high proportion, whereas human hazards and environmental hazards were reported for considerably fewer substances.
\end{abstract}

Keywords: Chemical safety, Hazardous chemicals, Hazard management, Registration

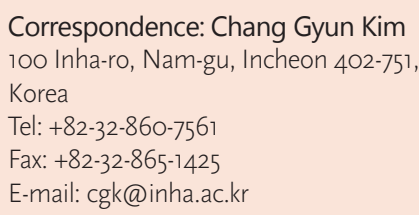

Received: January 9, 2015

Accepted: March 19, 2015

Published online: June 12, 2015

This article is available from: http://e-eht.org/

\section{Introduction}

The Act on the Registration and Evaluation, etc. of Chemical Substances (K-REACH) has been effective in the Republic of Korea (hereafter Korea) since January 1, 2015. According to the law, those who produce or import more than one ton of phasein substances yearly or any quantity of a new chemical substance must register at the National Institute of Environmental Research. Approximately 2000 types of phase-in substances are expected to be subject to registration, and the test data required for registration vary depending on the amount produced or im- ported (i.e., 15 test items for 1 to 10 tonnes, 26 items for 10 to 100 tonnes, 37 items for 100 to 1000 tonnes, and 47 items for greater than 1000 tonnes). If all test data were requested and acquired by the appropriate research institute, the predicted cost is 35 million Korean won (KRW) per substance for 1 to 10 tonnes, 96 million KRW for 10 to 100 tonnes, 410 million KRW for 100 to 1000 tonnes, and 1.03 billion KRW for greater than 1000 tonnes [1]. According to the K-REACH, multiple companies that attempt to register the same substance are required to produce a single set of test data and register jointly to minimize the registration cost for phase-in substances. In addition, when 
test data have previously been generated, permission from the owner of the corresponding test data should be obtained, either for a fee or at no cost. Considering that most of the phase-in substances subject to registration are produced or imported at volumes of great than 1000 tonnes, the cost of generating test data for the approximately 2000 kinds of phase-in substances subject to registration is expected to be 2.06 trillion KRW. The extent to which this enormous test cost can be reduced depends on the quantity of the existing test data and the cost of obtaining this data. In this study, we examined the current availability of test data that can be used for chemical substance registration in accordance with the K-REACH for 369 of 518 kinds of phasein substances subject to registration that were reported on October 31, 2014.

\section{Materials and Methods}

\section{Subjects}

For each of the 369 kinds of phase-in substances subject to registration out of 518 total kinds that were reported in October 2014, 47 test items (data regarding 13 physical and chemical properties, 15 human hazards, and 19 environmental hazards) that are required for chemical substance registration according to the K-REACH were examined (Table S1) [2].

\section{Methods}

Using 16 reference databases (DBs) that contain the test data for chemical substances, the availability of the existing test data for 47 test items and 369 kinds of phase-in substances subject to registration was assessed (Table S2).

Feasibility of existing test data for registration The reliability of the test data derived from the 16 reference DBs was classified according to such as the good laboratory practices (GLP) established by the Organization for Economic Cooperation and Development (OECD) (Table S3). If a test was objectively verified as meeting GLP regulations of the OECD, an international test guideline, or was published in Science Citation Index, it was assigned a reliability of 1 . If a test did not meet the requirements necessary to be assigned a reliability of 1 , but the methods were specified and scientifically validated, it was assigned a reliability of 2 . If a test was implemented without accredited methods or could not be scientifically validated, it was assigned a reliability of 3. For the test items in the K-REACH that only accept test data generated according to GLP regulations ( 1 item in physical and chemical properties, 15 items in human hazards, and 14 items in environmental hazards), only test data with reliability scores of 1 are likely to be approved. However, for the test items accept test date generated without following GLP regulations (12 items in physical and chemical properties and 5 items in environmental hazards), test data with reliability scores of 1 and 2 are likely to be approved.

\section{Results}

\section{Feasibility of Existing Test Data on Physical and Chemical Properties}

The existing test data on physical and chemical properties show that $2.1 \%$ of substances had test data with a reliability of 1 , $59.3 \%$ had data with a reliability of $2,0.9 \%$ had data with a reliability of 3 , and $37.7 \%$ of substances did not have test data. Assuming that only those with a reliability of 1 for the octanol-water partition coefficient are approved for phase-in substance registration based on the K-REACH, and that the existing test data with reliability scores of 1 and 2 for other test items are ap-

Table 1. Percentage of substances with existing test data on physical and chemical properties

\begin{tabular}{|c|c|c|c|c|c|}
\hline \multirow{2}{*}{ Classification } & \multicolumn{5}{|c|}{ Substances with existing test data (\%) } \\
\hline & Total & Reliability 1 & Reliability 2 & Reliability 3 & No data \\
\hline Physical state & $369(100)$ & $0(0.0)$ & $334(90.5)$ & $0(0.0)$ & $35(9.5)$ \\
\hline Water solubility & $369(100)$ & $16(4.3)$ & $312(84.6)$ & $1(0.3)$ & $40(10.8)$ \\
\hline Melting/freezing point & $369(100)$ & $13(3.5)$ & $306(82.9)$ & $2(0.6)$ & $48(13.0)$ \\
\hline Boiling point & $369(100)$ & $5(1.3)$ & $266(72.1)$ & $2(0.6)$ & $96(26.0)$ \\
\hline Vapor pressure & $369(100)$ & $13(3.5)$ & $264(71.5)$ & $1(0.3)$ & $91(24.7)$ \\
\hline Octanol-water partition coefficient & $369(100)$ & $27(7.3)$ & $209(56.6)$ & $0(0.0)$ & $133(36.1)$ \\
\hline Density & $369(100)$ & $5(1.4)$ & $171(46.3)$ & $6(1.6)$ & $187(50.7)$ \\
\hline Particle size & $369(100)$ & $0(0.0)$ & $0(0.0)$ & $0(0.0)$ & $369(100.0)$ \\
\hline Flammability & $369(100)$ & $14(3.8)$ & $209(56.6)$ & $13(3.5)$ & $133(36.0)$ \\
\hline Explosiveness & $369(100)$ & $5(1.3)$ & $285(77.2)$ & $8(2.2)$ & $71(19.3)$ \\
\hline Oxidation & $369(100)$ & $3(0.8)$ & $264(71.5)$ & $7(1.9)$ & $95(25.8)$ \\
\hline Viscosity & $369(100)$ & $0(0.0)$ & $142(38.5)$ & $1(0.3)$ & $226(61.2)$ \\
\hline Dissociation constant & $369(100)$ & $1(0.3)$ & $83(22.5)$ & $0(0.0)$ & $285(77.2)$ \\
\hline Total & $4797(100)$ & $102(2.1)$ & $2845(59.3)$ & $41(0.9)$ & 1809 (37.7) \\
\hline
\end{tabular}


Table 2. Percentage of substances with existing test data on human hazards

\begin{tabular}{|c|c|c|c|c|c|}
\hline \multirow{2}{*}{ Classification } & \multicolumn{5}{|c|}{ Substances with existing test data (\%) } \\
\hline & Total & Reliability 1 & Reliability 2 & Reliability 3 & No data \\
\hline Acute oral toxicity & $369(100)$ & $29(7.9)$ & $209(56.6)$ & $2(0.5)$ & $129(35.0)$ \\
\hline Revers mutation & $369(100)$ & $57(15.4)$ & $207(56.1)$ & $1(0.3)$ & $104(28.2)$ \\
\hline Skin irritation/corrosiveness & $369(100)$ & $40(10.8)$ & $169(45.8)$ & $1(0.3)$ & $159(43.1)$ \\
\hline Skin hypersensitivity & $369(100)$ & $30(8.1)$ & $100(27.1)$ & $3(0.8)$ & $236(64.0)$ \\
\hline Acute dermal toxicity & $369(100)$ & $16(4.3)$ & $156(42.3)$ & $3(0.8)$ & $194(52.6)$ \\
\hline Eye irritation/corrosiveness & $369(100)$ & $35(9.5)$ & $194(52.6)$ & $2(0.5)$ & $138(37.4)$ \\
\hline Chromosome aberration using mammalian culture cells & $369(100)$ & $29(7.7)$ & $150(40.6)$ & $1(0.3)$ & $189(51.2)$ \\
\hline Genetic toxicity using test animals & $369(100)$ & $31(8.4)$ & $130(35.2)$ & $1(0.3)$ & $207(56.1)$ \\
\hline Subacute toxicity (28 d) & $369(100)$ & $19(5.1)$ & $97(26.3)$ & $0(0.0)$ & $253(68.6)$ \\
\hline Reproductive and developmental toxicity & $369(100)$ & $21(5.7)$ & $139(37.7)$ & $1(0.3)$ & $208(56.3)$ \\
\hline $\begin{array}{l}\text { Additional genetic toxicity } \\
\text { (genetic toxicity of germ cells, etc.) }\end{array}$ & $369(100)$ & $7(1.9)$ & $53(14.4)$ & $0(0.0)$ & $309(83.7)$ \\
\hline Subchronic toxicity (90 d) & $369(100)$ & $57(15.4)$ & $207(56.1)$ & $1(0.3)$ & $104(28.2)$ \\
\hline Teratogenicity & $369(100)$ & $22(6.0)$ & $116(31.4)$ & $0(0.0)$ & $231(62.6)$ \\
\hline 2nd generation reproductive toxicity & $369(100)$ & $12(3.2)$ & $52(14.1)$ & $0(0.0)$ & $305(82.7)$ \\
\hline Carcinogenicity & $369(100)$ & $64(17.3)$ & $108(29.3)$ & $0(0.0)$ & $197(53.4)$ \\
\hline Total & $5535(100)$ & $469(8.5)$ & $2087(37.7)$ & $16(0.3)$ & $2963(53.5)$ \\
\hline
\end{tabular}

Table 3. Possibility of utilizing existing test data on environmental hazards

\begin{tabular}{|c|c|c|c|c|c|}
\hline \multirow{2}{*}{ Classification } & \multicolumn{5}{|c|}{ Substances with existing test data (\%) } \\
\hline & Total & Reliability 1 & Reliability 2 & Reliability 3 & No data \\
\hline Fish acute toxicity & $369(100)$ & $66(17.9)$ & $171(46.3)$ & $0(0.0)$ & $132(35.8)$ \\
\hline Biodegradation (ready) & $369(100)$ & $100(27.1)$ & $92(24.9)$ & $1(0.3)$ & $176(47.7)$ \\
\hline Water flea acute toxicity & $369(100)$ & $81(21.9)$ & $160(43.4)$ & $0(0.0)$ & $128(34.7)$ \\
\hline Fresh water algae growth inhibition & $369(100)$ & $52(14.1)$ & $105(28.4)$ & $0(0.0)$ & $212(57.5)$ \\
\hline pH-dependent hydrolysis & $369(100)$ & $4(1.1)$ & $150(40.6)$ & $0(0.0)$ & $215(58.3)$ \\
\hline Biodegradation (inherent) & $369(100)$ & $39(10.6)$ & $16(4.3)$ & $3(0.8)$ & $311(84.3)$ \\
\hline Verification of degradation product & $369(100)$ & $0(0.0)$ & $14(3.8)$ & $1(0.3)$ & $354(95.9)$ \\
\hline Fish chronic toxicity & $369(100)$ & $6(1.6)$ & $66(17.9)$ & $0(0.0)$ & $297(80.5)$ \\
\hline Water flea chronic toxicity & $369(100)$ & $25(6.8)$ & $72(19.5)$ & $0(0.0)$ & $272(73.7)$ \\
\hline Land plant acute toxicity & $369(100)$ & $7(1.9)$ & $61(16.5)$ & $0(0.0)$ & $301(81.6)$ \\
\hline Land invertebrate acute toxicity & $369(100)$ & $12(3.3)$ & $38(10.3)$ & $0(0.0)$ & $319(86.4)$ \\
\hline Activated sludge respiration inhibition & $369(100)$ & $34(9.2)$ & $18(4.9)$ & $0(0.0)$ & $317(85.9)$ \\
\hline Adsorption and desorption & $369(100)$ & $2(0.5)$ & $177(48.0)$ & $0(0.0)$ & $190(51.5)$ \\
\hline Additional information on environmental behavior and movement & $369(100)$ & $0(0.0)$ & $0(0.0)$ & $0(0.0)$ & $369(100.0)$ \\
\hline Land plant chronic toxicity & $369(100)$ & $2(0.5)$ & $29(7.9)$ & $0(0.0)$ & $338(91.6)$ \\
\hline Land invertebrate chronic toxicity & $369(100)$ & $4(1.1)$ & $22(6.0)$ & $0(0.0)$ & $343(92.9)$ \\
\hline Additional information on adsorption and desorption & $369(100)$ & $0(0.0)$ & $1(0.3)$ & $0(0.0)$ & $368(99.7)$ \\
\hline Benthos chronic toxicity & $369(100)$ & $0(0.0)$ & $7(1.9)$ & $0(0.0)$ & $362(98.1)$ \\
\hline Bioaccumulation & $369(100)$ & $24(6.5)$ & $178(48.2)$ & $0(0.0)$ & $167(45.3)$ \\
\hline Total & $7011(100)$ & $458(6.5)$ & $1377(19.6)$ & $5(0.1)$ & $5171(73.8)$ \\
\hline
\end{tabular}

proved, the probability that the existing test data on physical and chemical properties can be utilized is $57.1 \%$ (Table 1 ).

\section{Feasibility of Existing Test Data on Human Hazards}

Based on the existing test data on human hazards, it can be concluded that $8.5 \%$ of substances had test data with a reliability of $1,37.3 \%$ had data with a reliability of $2,0.3 \%$ had data with a reliability of 3 , and $53.5 \%$ did not have test data. Assuming that only the existing testing data with reliability scores of 1 are ap- proved for phase-in substance registration according to the guidelines of the K-REACH, the probability that the existing test data on human hazards can be utilized is $8.5 \%$ (Table 2).

\section{Feasibility of Existing test Data on Environmental Hazards}

The existing test data on environmental hazards show that $6.5 \%$ of substances had test data with a reliability of $1,19.6 \%$ had data with a reliability of $2,0.1 \%$ had data with a reliability of 3 , and 
$73.8 \%$ did not have test data. Assuming that the existing test data with reliability scores of 1 and 2 for $\mathrm{pH}$-dependent hydrolysis, verification of degradation product, adsorption and desorption, additional information on environmental behavior and movement, and additional information on adsorption and desorption are approved for phase-in substance registration according to the guidelines of K-REACH, and that only those with reliability scores of 1 for other test data are approved, the probability that existing test data on environmental hazards can be utilized is $11.8 \%$ (Table 3 ).

\section{Discussion}

We analyzed the possibility of utilizing the existing test data contained in 16 reference DBs for 369 of 518 kinds of phase-in substances subject to registration that were reported in October 2014. The physical and chemical properties were available for $57.1 \%$ of substances, whereas data regarding human hazards and environmental hazards were available at considerably lower rates, $8.5 \%$ and $11.8 \%$, respectively. Our analysis of the use of the existing test data was limited to 16 reference DBs; therefore, additional data may be obtained by using the other DBs. Chemical companies that need to register phase-in substances accord- ing to the K-REACH should use the existing test data to minimize registration costs.

\section{Acknowledgements}

This study was supported by the Korea Ministry of Environment (MOE) as “MOE's R\&D Program on environmental technology development” (no. 412-111-005).

\section{Conflict of Interest}

The authors have no conflicts of interest with material presented in this paper.

\section{References}

1. Lee J. Cost-benefit analysis (focused on direct expense) according to the enactment of the 'Act on the Registration \& Evaluation, etc. of Chemical Substances' [dissertation]. Seoul: Korea University; 2012 (Korean).

2. Ministry of Government Legislation. Act on the Registration and Evaluation, etc. of Chemical Substances [cited 2015 Mar 31]. Available from: http://www.law.go.kr/lsInfoP.do?lsiSeq=140402\#0000 (Korean). 
Table S1. Test items required for chemical substance registration

\begin{tabular}{|c|c|}
\hline Classification & Test items \\
\hline Physical and chemical properties (13 items) & $\begin{array}{l}\text { Physical state, water solubility, melting/freezing point, boiling point, vapor pressure, octanol-water partition coefficient, } \\
\text { density, particle size, flammability, explosiveness, oxidation, viscosity, dissociation constant }\end{array}$ \\
\hline Human hazards (15 items) & $\begin{array}{l}\text { Acute oral toxicity (acute inhalation toxicity), revers mutation, skin irritation/corrosiveness, skin hypersensitivity, acute } \\
\text { dermal toxicity (acute inhalation toxicity), eye irritation/corrosiveness, chromosome aberration using mammalian } \\
\text { culture cells, genetic toxicity using test animals, subacute toxicity ( } 28 \text { days), reproductive and developmental toxicity, } \\
\text { additional genetic toxicity (genetic toxicity of germ cells, etc.), subchronic toxicity ( } 90 \text { days), teratogenicity, 2nd- } \\
\text { generation reproductive toxicity, carcinogenicity }\end{array}$ \\
\hline Environmental hazards (19 items) & $\begin{array}{l}\text { Fish acute toxicity, biodegradation (ready), water flea acute toxicity, freshwater algae growth inhibition, pH-dependent } \\
\text { hydrolysis, biodegradation (inherent), verification of degradation product , fish chronic toxicity, water flea chronic } \\
\text { toxicity, land plant acute toxicity, land invertebrate acute toxicity, activated sludge respiration inhibition, adsorption } \\
\text { and desorption, additional information on environmental behavior and movement, land plant chronic toxicity, land } \\
\text { invertebrate chronic toxicity, additional information on adsorption and desorption, benthos chronic toxicity, } \\
\text { bioaccumulation }\end{array}$ \\
\hline
\end{tabular}


Table S2. Reference databases (DBs)

\begin{tabular}{|c|c|c|c|c|}
\hline \multirow[b]{2}{*}{ Reference DB } & \multirow[b]{2}{*}{ DB website } & \multicolumn{3}{|c|}{ Test data available } \\
\hline & & $\begin{array}{c}\text { Physical and } \\
\text { chemical properties }\end{array}$ & Human hazards & $\begin{array}{c}\text { Environmental } \\
\text { hazards }\end{array}$ \\
\hline NCIS (Korea) & ncis.nier.go.kr & ○ & ० & O \\
\hline Safety test (Korea) & ncis.nier.go.kr & ○ & ○ & O \\
\hline OECD SIDS (EU) & www.chem.unep.ch/irptc/sids/OECDSIDS/indexcasnumb.htm & ○ & o & O \\
\hline GHS classification result (EU) & esis.jrc.ec.europa.eu/index.html & O & ○ & O \\
\hline GHS classification result (Korea) & ncis.nier.go.kr/ghs/search/toxic_contain_chem_label.jsp & O & o & O \\
\hline ECB IUCLID (EU) & esis.jrc.ec.europa.eu/ & O & o & O \\
\hline HSDB (USA) & toxnet.nlm.nih.gov/newtoxnet/hsdb.htm & O & o & O \\
\hline IPCS EHCs (EU) & http://www.inchem.org/pages/ehc.html & - & ○ & O \\
\hline ATSDR (USA) & www.atsdr.cdc.gov/toxprofiles/index.asp & - & o & - \\
\hline $\begin{array}{l}\text { Japan safety } \\
\text { Evaluation report (Japan) }\end{array}$ & $\begin{array}{l}\text { www.safe.nite.go.jp/english/sougou/view/ } \\
\text { TotalSrchlnput_en.faces }\end{array}$ & - & ○ & O \\
\hline CCRIS (USA) & toxnet.nlm.nih.gov/cgi-bin/sis/htmlgen?CCRIS & - & ० & - \\
\hline GENETOX (USA) & toxnet.nlm.nih.gov/cgi-bin/sis/htmlgen?GENETOX & - & o & - \\
\hline EPA IRIS (USA) & cfpub.epa.gov/ncea/iris/index.cfm?fuseaction=iris.showsubstanceList & - & o & - \\
\hline ECOTOX (USA) & cfpub.epa.gov/ecotox/quick_query.htm & - & - & O \\
\hline Chemical DB (USA) & ull.chemistry.uakron.edu/erd/ & O & - & - \\
\hline ChemIDplus (USA) & chem.sis.nlm.nih.gov/chemidplus/chemidlite.jsp & O & - & - \\
\hline Total & 16 & 9 & 13 & 10 \\
\hline
\end{tabular}


Table S3. Judgment criteria for reliability

\begin{tabular}{ll}
\hline Reliability & \multicolumn{1}{c}{ Judgment criteria } \\
\hline 1 & Reliable without restrictions: the test data was carried out in \\
& accordance with the GLP regulations or published in $\mathrm{SCl}$ \\
2 & Reliable with restrictions: the test data was not carried out in \\
& accordance with the GLP regulations or published in SCl. \\
& However, the test data were produced by scientifically valid \\
& methods \\
& Not reliable: test data produced by methods that are not \\
& scientifically valid
\end{tabular}

GLP, good laboratory practice; SCI, Science Citation Index. 